\title{
Escola sem fronteiras: educação superior para a sociedade digital
}

School without frontiers: university education for the digital society

Escuela sin fronteras: educación superior para la sociedad digital

Maria Carolina Garcia

- Doutora em Comunicação e Semiótica pela Pontifícia Universidade Católica de São Paulo (PUC-SP)

- Mestre em Comunicação e Semiótica pela PUC-SP

- Bacharel em Comunicação Social - Jornalismo pela Universidade Federal do Paraná (UFPR)

- Docente do Centro Universitário Belas Artes de São Paulo (Febasp)

- Coordenadora do Curso Superior de Tecnologia em Mídias Sociais Digitais da Febasp

- Coordenadora da Pós-graduação Lato Sensuem Comunicação Corporativa e Redes Sociais da Febasp

- Pesquisadora ligada ao Centro Interdisciplinar de Semiótica da Cultura e das Mídias da PUC-SP

- Autora de Imagens errantes: ambiguidade, resistência e cultura de moda (Estação das Letras e Cores, 2010)

- 23 anos de experiência em comunicação para negócios de moda e estilo de vida

- E-mail: maria.garcia@belasartes.br 


\section{Resumo}

Este artigo apresenta o desafio enfrentado pelas instituições de ensino superior na elaboração de ofertas educacionais específicas para o campo das mídias sociais digitais, entendidas como vetor de desenvolvimento da economia criativa. 0 estudo considera o conceito de economia criativa propagado por Howkins (2012) e Florida (2011), bem como as noções de sociedade em rede de Castells (2003) e Recuero (2009). Como resultado, aponta o entrelaçamento entre comunicação e economia criativa no setor educacional, contextualizando as mídias sociais digitais como área que exige formação multidisciplinar, direcionada à classe criativa.

\section{PALAVRAS-CHAVE: COMUNICAÇÃO・ECONOMIA CRIATIVA • MÍDIAS SOCIAIS DIGITAIS・EDUCAÇÃO SUPERIOR・CLASSE CRIATIVA.}

\section{Abstract}

This article presents the challenge faced by higher education institutions in the development of specific educational offerings for the field of digital social media, understood to be the development vector of creative economics. The study considers the concept of creative economics as divulged by Howkins (2012) and Florida (2011), as well as notions of a network society by Castells (2003) and Recuero (2009). As a result, it points out the interlacing between communication and creative economics in the education sector, contextualizing the digital social media as an area that requires multidisciplinary education directed towards the creative class.

\section{KEYWORDS: COMMUNICATION・CREATIVE ECONOMICS・DIGITAL SOCIAL MEDIA •HIGHER EDUCATION •CREATIVE CLASS.}

\section{Resumen}

Ese artículo presenta los desafíos enfrentados por las instituciones de educación superior en la elaboración de ofertas educacionales específicas para el campo de los medios sociales digitales, comprendidos como un vector del desarrollo de la economía creativa. El estudio considera el concepto de economía creativa según lo difunden Howkins (2012) y Florida (2011); así como las nociones de sociedad en red de Castells (2003) y Recuero (2009). Como resultado, se apunta el entrelazamiento entre comunicación y economía creativa en el sector educacional, contextualizando los medios sociales digitales como área que exige una formación multidisciplinaria, direccionada a la clase creativa. 
"A qualidade não é medida simplesmente em anos de educação, mas em tipo de educação" (Castells, 2003, p. 77).

A fórmula é aparentemente simples. Somem-se um pedaço de papelão dobrável, duas lentes, um microchip, um ímã, um elástico, duas fitas de velcro, um aplicativo e um smartphone. Na temporada de moda outono-inverno 2015, a rede varejista gaúcha Renner apresentou seus lançamentos à imprensa e a formadores de opinião por meio do Google Cardboard, instrumento lançado pela empresa norte-americana durante a conferência anual para desenvolvedores Google I/0, em junho de 2014.

A ferramenta, que pode até ser montada em casa, permitiu aos influenciadores visualizarem, ao lado das roupas e acessórios, o painel de referências que norteou o processo criativo dos estilistas da marca. Os convidados puderam conhecer da trilha sonora às referências imagéticas que direcionaram a criação da coleção, selecionando suas preferências por meio do Google Cardboard (Google Think, 2015).

Com essa ação de compartilhamento interativo, as lojas Renner, que há haviam utilizando o Google Glass em lançamento anterior, buscaram democratizar o acesso público a um conteúdo antes compartilhado somente no âmbito do departamento criativo da empresa'. Posteriormente, esse mesmo material foi utilizado pela marca em suas redes sociais, no blog e no YouTube, inspirando a companhia a incluir a ação em algumas de suas lojas, em virtude do intenso engajamento dos membros dessas comunidades virtuais na difusão da atividade.

Quase simultaneamente, a estilista paulistana, designer de moda, Fernanda Yamamoto decidiu abrir as portas de seu atelier para que um grupo maior de pessoas - cerca de 15, em média - pudesse conhecer o processo de elaboração de suas coleções, por meio de interação presencial com a equipe de trabalho responsável pela confecção das peças.

Em entrevista durante visita técnica ao ateliê de Yamamoto, a profissional explicou que, em seu entender, tal momento de visitação gera uma vinculação afetiva única entre marca e cliente, pois o compartilhamento torna a experiência memorável, valorizando o processo de desenvolvimento da coleção tanto quanto o resultado final.

Para a estilista Fernanda Yamamoto, conforme os comentários emitidos na entrevista, as mídias sociais digitais auxiliaram a construir um novo modelo de compartilhamento que traz à tona o desejo do consumidor de construir redes de relacionamento on-line e off-line, e isso exige a implementação de novas estratégias comunicacionais.

A atividade iniciou-se na primavera-verão de 2015 e, na temporada seguinte, o sucesso foi tamanho que várias seções de visitas, antes limitadas à clientela habitual, tiveram de ser agendadas. Isso porque fotos, vídeos e comentários sobre a iniciativa, uma vez disseminados pelos próprios visitantes nas mídias sociais digitais, despertaram o interesse de outros usuários de redes como Facebook e Instagram, desdobrando-se em posts nos principais blogs ligados à moda e ao estilo de vida.

1 Realizada em janeiro de 2015, a estratégia de comunicação desenvolvida pela Renner com o Google Cardboard foi apresentada por Maíra Ramos, executiva de contas para o segmento de moda do Google, em palestra proferida no curso de Negócios da Moda da Universidade Anhembi Morumbi, em São Paulo, em 11/3/2015, com mediação da autora deste artigo. Para mais informações, sugere-se consultar http://thinkwithgoogle.com.br, onde a ação é apresentada por meio de estudo de caso.

2 A entrevista em profundidade com Fernanda Yamamoto foi realizada pela autora durante visita técnica de alunos da graduação tecnológica em Mídias Sociais Digitais do Centro Universitário Belas Artes de São Paulo ao ateliê dela, situado na Vila Madalena, em São Paulo, em 25/4/2015. A interação com o mercado por meio de visitas técnicas e aulas externas é parte da pedagogia ativa que norteia o curso. 


\section{COMPARTILHAR E APRENDER}

E o que marcas com visões tão distintas quanto Fernanda Yamamoto e Renner têm em comum?

O avanço da internet mudou a maneira como as informações são consumidas, e foi graças a ela que, segundo Moore (2013, p. 124), o compartilhamento tornou-se disseminado, instantâneo e acessível, criando também redes de aprendizagem colaborativa.

Essa situação, por sua vez, gera a demanda por procedimentos de curadoria, já que o excesso de informação se faz também presente.

De fato, estamos vivendo um momento surpreendente na história da humanidade. Instituições familiares, capazes de prover estabilidade, segurança e oportunidade por séculos, estão passando por mudanças vertiginosas, muitas das quais causadas pelo progresso tecnológico. Some-se ainda o avanço do comércio internacional, da logística e do varejo, bem como da indústria do entretenimento, que sublinharam o reconhecimento da internet e das mídias sociais digitais como ingredientes de alta relevância nos trâmites da comunicação global.

'Mídia', oriunda da palavra latina media, plural de medium, é um termo tão complexo que carrega camadas de significações, embora medium, que vem de 'medhyo', em indo-europeu, tenha o significado simples de 'aquilo que fica no meio'. Para Baitello (2009, p. 60), "mídia é o meio de campo que procura superar o abismo entre o eu e o outro". Nesse sentido, a transcendência espacial dada pelo mundo digital amplia a capacidade humana de atuar em diferentes atividades e locais do mundo simultaneamente, expandindo o cenário midiático.

Dessa feita, o universo digital vem possibilitando inúmeras convergências, palavra que também estáligada às transformações mercadológicas, culturais e sociais. Segundo Jenkins (2009, p. 43),

a convergência das mídias é mais do que apenas uma mudança tecnológica. A convergência altera a relação entre tecnologias existentes, indústrias, mercados, gêneros e públicos. A convergência altera a lógica pela qual a indústria midiática opera e pela qual os consumidores processam a notícia e o entretenimento.

Essa situação propicia o surgimento de redes sociais, que são grupos ligados por relações sociais estruturadas por pessoas com um interesse em comum. As mídias sociais digitais enquadram-se nesse contexto, uma vez que são meios pelos quais as redes sociais são construídas e o conteúdo on-line é compartilhado e propagado por meio de interações sociais reativas (Recuero, 2009, p. 40).

É importante salientar, seguindo o raciocínio de Jenkins (2009, p. 43), que a convergência não se dá por meio dos aparelhos em si, por mais sofisticados que venham a ser. A convergência ocorre dentro dos cérebros de indivíduos e em suas interações sociais com outros (Jenkins, 2009, p. 30), o que nos leva a crer na importância da contribuição acadêmica no sentido de pesquisa e estudar, em sala de aula, a complexidade dessas interações. Ainda segundo Jenkins (2009, p. 30), o modo como essas diversas transições evoluem irá determinar o equilíbrio de poder na próxima era dos meios de comunicação.

Rocamora (2011), Santaella e Lemos (2010), Kotler, Kartajaya e Setiawan (2010) e Recuero (2009) acrescentam que um dos fatores que permitiram a nova onda de tecnologia foi precisamente a ascensão das mídias sociais digitais. Esses autores até mesmo sublinham duas categorias distintas: as expressivas - blogs, Twitter, YouTube, Instagram, Facebook, sites para 
compartilhamento de fotografias como o Flickr e outros sitesde networkingsocial; e as colaborativas - que incluem ambientes virtuais como Wikipédia e Craigslist. Jenkins (2009, p. 50) atenta para o fato de que os consumidores estão aprendendo a utilizar essas multiplataformas para interagir, provocando expectativas de um fluxo mais livre de ideias, destacando a construção de uma inteligência coletiva, da qual nos fala Lévy (2000, p. 28). Para Pierre Lévy (2000, p. 28-30), os outros são fonte de conhecimento e existe uma inteligência coletiva, capaz de mobilizar competências, que está distribuída por toda parte e é altamente valorizada, especialmente por meio de sua coordenação em tempo real. Essa situação parece ser facilitada pelo uso da internet e pelo amplo acesso às mídias sociais digitais, notadamente considerando o público jovem.

No Brasil, essa situação é confirmada por dados da Pesquisa Brasileira de Mídia 2014, realizada pela Secretaria de Comunicação da Presidência da República (Secom). A investigação (Secom, 2014), que entrevistou 18.312 brasileiros em 848 municípios entre outubro e novembro de 2013, aponta que 47\% dos brasileiros têm o hábito de acessar a internet, sendo que há fortes indícios de que esse número deva aumentar nos próximos anos, sobretudo entre os jovens. Ainda segundo a mesma fonte, os segmentos que passam mais tempo on-line a cada contato, tanto de $2^{\underline{a}}$ feira a $6^{\underline{a}}$ feira, quanto nos fins de semana, tendem a ser os mesmos que utilizam a internet com mais frequência: justamente as faixas etárias mais jovens, os moradores de grandes centros urbanos e os estratos de maior renda e escolaridade. Esse aspecto, em nosso entender, é relevante em termos da reflexão acadêmica sobre novas ofertas educacionais no campo das mídias sociais digitais.

\section{GERAÇÕES HIPERCONECTADAS E ECONOMIA CRIATIVA}

Ao analisarmos a primeira década da world wide web, constatamos que se tratava de um espaço utilizado com maior frequência por amantes da tecnologia e profissionais especializados. No entanto, com a ascensão das mídias sociais digitais no início dos anos 2000, a internet se transformou completamente, com a maioria dos conteúdos com os quais o usuário interage sendo produzidos em rede, por outros usuários, muitos dos quais praticamente leigos em termos tecnológicos.

Toda essa mudança desenvolveu-se com a geração Y, ou dos millenials, que neste momento chega à vida adulta exposta a um conjunto único de eventos que define seu lugar na história e molda suas perspectivas. A geração Y é composta por pessoas que nasceram nos anos 1980 (apesar de alguns autores incluírem nessa geração pessoas que nasceram no final da década de 1970); enquanto a geração Z é representada por pessoas que nasceram na década de 1990.

A geração Z, ou "geração digital", é fortemente influenciada pela tecnologia e permanece hiperconectada, tendo entre seus influenciadores personalidades que transformaram, com suas iniciativas, o mundo digital, tais como Mark Zuckerberg (Facebook) e Mike Krieger (Instagram). Estabeleceu, desde muito cedo, o convívio com os aparatos tecnológicos, e, desse modo, vem contribuindo na produção de uma vida inteiramente diferente das anteriores.

De acordo com a pesquisa "O sonho brasileiro", realizada pela empresa Box 1824 (2012) ${ }^{3}$, essa geração tem foco no tempo presente, valoriza a cultura global como um mosaico de culturas locais, desenvolveu um pensamento não hierárquico, acredita na essência colaborativa dos novos vínculos sociais, confia na presença independente de espaço físico e é capaz de gerar multiplicidade de projetos, além de possuir facilidade de ingressar em grupos de ação temporários.

3 A fase qualitativa da pesquisa compreendeu 1.200 entrevistas de grupo com jovens em São Paulo, Rio de Janeiro, Porto Alegre e Recife. A fase quantitativa, liderada pelo Instituto Datafolha, incluiu entrevistas em 173 cidades, localizadas em 23 estados brasileiros, entre 7 e 15 de outubro de 2010. 
Os jovens experimentam hábitos inéditos de comunicação, dispondo de aparatos tecnológicos com os quais lidam em meio a outras atividades (cursos, lazer etc.). Esses hábitos são anunciados como sinais de uma mudança de comportamento mais geral que se estende às formas de aprender e relacionar-se com as tarefas diárias.

Nesse sentido, a pesquisa "O sonho brasileiro" aponta que o Brasil está vivenciando um momento único, propício para 0 surgimento desse cidadão. Segundo a pesquisa, existem 25 milhões de jovens brasileiros entre 18 e 24 anos que nasceram em um país sem preocupações com a ditadura e a inflação, mas com o sentimento de prosperidade.

A agência Box 1824 define-os como a primeira geração global de brasileiros, que traz uma nova maneira de se relacionar em um mundo sem fronteiras. Enviar e receber e-mails, fazer pesquisas, participar de chats, baixar músicas, vídeos e jogos, conversar com amigos em programas de mensagens ou mesmo atualizar os próprios blogs. tais jovens fazem isso quase simultaneamente.

Esses indivíduos possuem características comportamentais diferenciadas, que vão muito além daquelas definidas em termos gerais quando o assunto é escolha profissional. Nesse aspecto, fatores tais como maior identificação com a profissão do que com a empresa, seguir carreira no sentido horizontal, possuir horários flexíveis, trabalhar num ambiente de moderno e informal, entre outros, adquirem relevância.

Esse grupo quer ser pago para criar, e não apenas para executar tarefas já planejadas, agregando valor econômico mediante a criatividade, ou seja, mostrando que a criação gera lucro. Dessa forma, fica claro, segundo Florida (2011), que o trabalho criativo, essência da economia atual, não pode ser padronizado, de modo a abrir as portas para a inovação, seu principal produto.

No século XVIII, um sinal visível da aceleração social foi a criação de jornais diários (Rosa, 2010, p. 149). No século XXI, conforme exposto inicialmente, foi a internet que instigou um novo ritmo na circulação de notícias.

Os blogs romperam a temporalidade cíclica do noticiário, assim como sua impessoalidade, mediante um loop de feedbacks virtuais contínuos e incessantes, que sugere que apenas uma leitura diária não é suficiente (Rosa, 2010, p. 149). Ao contrário, entrar e sair de ambientes digitais converteu-se na norma, já que esse tipo de mídia instiga um novo ritmo e uma nova inquietude, além de outras rotinas no consumo de notícias. Os leitores on-line alocam curtos períodos de tempo para ler, favorecendo a mudança entre páginas web e distintas fontes. Tal comportamento inclui leituras simultâneas e uso de mais de uma tela como fonte de informação (incluindo computadores, televisões, tablets e smartphones).

Se a visita media por página dura um pouco menos de um minuto (Nielson, 2011), conteúdos elaborados para esses ambientes precisam ser curtos. Além de concisos, devem ter consciência da prevalência da mudança, necessidade de flexibilidade e importância da rapidez que, segundo Florida (2011, p. 147), são inerentes ao cenário da economia criativa, conceito cunhado pelo especialista inglês John Howkins (2012, p. 10), mentor do Centro Universitário Belas Artes de São Paulo, a primeira instituição de ensino nacional a apostar na formação superior do profissional atuante em mídias sociais digitais. É o exemplo de tal curso $^{4}$, nascido nesse contexto, que tomaremos para a análise a seguir.

Em palestra proferida durante o Fórum Belas Artes de Economia Criativa, John Howkins ${ }^{5}$ observou que o mundo está presenciando o nascimento, ou a ascensão, de uma sociedade com uma nova cultura que possui um estilo de vida

40 curso, que conta com a mentoria especializada da executiva Alice Ferraz, criadora da plataforma de bloggers FHits, iniciou suas atividades em fevereiro de 2015, contabilizando 59 estudantes dentre as 60 vagas ofertadas.

5 A palestra "Tendências globais da economia criativa" foi proferida por John Hownkins no encerramento do Fórum Belas Artes de Economia Criativa, realizado em 22/9/2015, no auditório do Centro Universitário Belas Artes, em São Paulo. 
diferenciado. Tal situação nos leva a crer que a formação profissional da geração Y e, sobretudo, da geração Z, está pautada pelo cenário da economia criativa.

Na ocasião, o pesquisador britânico sinalizou, precisamente, que existem dois tipos de criatividade: aquela que se relaciona ao cumprimento de perspectivas individuais e a do tipo que gera produtos para os outros. 0 primeiro é uma característica universal da humanidade e é encontrado em todas as sociedades e culturas. 0 segundo é mais forte nas sociedades industriais, que colocam um valor mais alto na novidade, na ciência e na inovação tecnológica, e sobre os direitos de propriedade intelectual. Isso nos leva a crer que a relação entre criatividade e economia possibilita, mediante a combinação de ambos, um manancial extraordinário de riqueza e valor.

\section{FORMAÇÃO SUPERIOR PARA A CLASSE CRIATIVA}

De acordo com a Federação do Comércio do Estado de São Paulo (Fecomércio, 2010), multidisciplinaridade, diversidade, pensamento global, velocidade e compartilhamento são as principais características da era da criatividade, permeados pela presença da tecnologia e das mídias sociais digitais enquanto elemento ativador, como apresentado no caso da Renner e seu uso do Google Cardboard.

"Na economia criativa, tempo é o único recurso não renovável" (Florida, 2011, p. 147), o que pressupõe contínua tentativa de economia desse recurso mediante o uso de muitas ferramentas simultâneas, que passam a estar presentes também na relação de ensino-aprendizagem, a exemplo do que demonstra a estilista Fernanda Yamamoto.

A comunicação digital, entendida como processo dinâmico de reoperação conceitual e vivência prática efetiva, inclui a cultura como base do estilo de vida contemporâneo, fundamentando os vínculos entre emissores e receptores de mensagens.

Pouco a pouco, as instituições de ensino superior vêm se engajando nesse movimento. Isso se dá por meio da ampliação de atividades de educação à distância (EaD) e do próprio uso das mídias sociais digitais como ambiente de pesquisa acadêmica em sala de aula, enquanto elemento integrador de conteúdos multidisciplinares construídos e reconstruídos pelo próprio aluno mediante sua interação em redes sociais. Nesse sentido, instituições de ensino e seu corpo docente atuam como influenciadores do cenário digital, uma vez que opiniões e comentários extrapolam a sala de aula.

Considerando tal contexto, o Curso Superior de Tecnologia em Mídias Sociais Digitais do Centro Universitário Belas Artes de São Paulo visa desenvolver e aprimorar o profissional para atuar em atividades de produção, análise, metrificação e monetização de conteúdo em mídias sociais digitais, de forma a estimular, ampliar, enriquecer e melhorar qualitativamente a atuação em diversos campos ligados à área.

Para estar apto a desenvolver atividades nesse mercado, o profissional deve circular num abrangente campo de conhecimento que inclua o entendimento da sociedade digital, metodologia de pesquisa criativa, pesquisa de tendências e comportamento, enriquecimento de repertório cultural, possibilidades de transversalização do campo da tecnologia, habilidade de comunicação e expressão em multiplataformas, potencialidade curatorial e domínio estético para direção de arte, além de gestão e monetização de conteúdo on-line. 
Logo, os componentes curriculares buscam a inovação criativa como recurso econômico, colocando-a no centro do discurso social e financeiro, já que a economia criativa se fundamenta precisamente em atualizar indústrias de forma social e ambientalmente responsável, criando sinergia entre a sociedade e os indivíduos e gerando capital simbólico.

Castells (2003, p. 77) reconhece que,

\begin{abstract}
assim, por um lado as firmas comerciais têm acesso a um extraordinário volume de informação que - com a ajuda de armazenamento magnético, processamento digital e a internet - podem recombinar e aplicar para todos os fins e em todos os contextos. Por outro lado, isso põe uma pressão extraordinária sobre o trabalho. A economia eletrônica não pode funcionar sem profissionais capazes de navegar, tanto tecnicamente quanto em termos de conteúdo, nesse profundo mar de informação, organizando-o, focalizando-o e transformando-o em conhecimento específico, apropriado para a tarefa e o objetivo do processo de trabalho. Profissionais desse tipo devem ter alto nível de instrução e iniciativa.
\end{abstract}

0 mesmo autor completa que talento é a chave da produção em negócios eletrônicos e esse talento precisa ser desenvolvido num ambiente favorável, que agregue conhecimento determinante para a sociedade digital: "Na economia eletrônica, os profissionais devem ser capazes de se programar em habilidades, conhecimento e pensamento segundo tarefas mutáveis num ambiente empresarial em evolução" (Castells, 2003, p. 78). Santaella e Lemos (2010, p. 16) parecem concordar com esse direcionamento, quando refletem que a economia global é hoje constituída pelas trocas e fluxos quase instantâneos de informação, capital e comunicação cultural.

Na elaboração de conteúdos educativos, portanto, é preciso atentar que devem ser direcionados aos indivíduos criativos, que Florida (2011) denomina "classe criativa". Conforme Castells (2003, p.82), "flexibilidade no trabalho, padrões variáveis de emprego, diversidade das condições de trabalho e individualização das relações de trabalho são características sistêmicas dos negócios eletrônicos".

Tal análise propicia entender os motivos pelos quais as mídias sociais digitais integram um dos setores que convergem para a dinamização da economia criativa, conforme a categorização da Unctad (sigla em inglês, para United Nations Conference On Trade and Development), que inclui as chamadas "novas mídias" (Unctad, 2010, p. 8). A Unctad trata a economia criativa como um conceito em evolução, com base em recursos criativos potencialmente geradores de crescimento, incorporando a proposição de que o desenvolvimento econômico e cultural não são fenômenos separados ou não relacionados, mas que fazem parte de um processo mais amplo de desenvolvimento sustentável. Engloba, portanto, aspectos econômicos, culturais e sociais que interagem com a tecnologia. Em particular, no Brasil, a formalização de uma secretaria de governo, a Secretaria de Economia Criativa (SEC), associada ao Ministério da Cultura (MinC), denota a relevância do setor para instituições públicas e privadas, fatores que apontam para uma possível demanda de oferta educacional compatível.

As indústrias criativas que utilizam esses recursos não só permitem que os países contem suas próprias histórias e projetem suas identidades culturais para si e para o mundo, mas também proporcionam a eles uma fonte econômica, por meio da criação de empregos qualificados, crescimento e aumento da renda global, além de irradiar benefícios para outros setores da economia (Unctad, 2010).

Por outro lado, os negócios se beneficiam desse novo cenário. No Brasil, o 31ํRelatório WebShoppers 6 registrou que o comércio eletrônico nacional faturou R\$35,8 bilhões em 2014, um crescimento nominal de 24\%, já que em 2013 o resultado foi de R\$

60 relatório WebShoppers utiliza informações provenientes de pesquisas realizadas pela E-bit junto a 21.000 lojas virtuais e ao seu painel de e-consumidores, além de pesquisas ad hoc e informações externas. 
28,8 bilhões (Webshoppers, 2015, p. 8). Segundo a mesma fonte, 61,6 milhões de brasileiros já fizeram alguma compra on-line. Destes, 51,5 milhões fizeram pelo menos uma compra em 2014, com ênfase no uso de smartphones (65\%) e tablets (35\%).

O relatório destaca ainda que a categoria Moda e Acessórios lidera as vendas (17\% do volume total de pedidos), sendo seguida por Cosméticos e Perfumaria (15\%), o que indica que as plataformas de comunicação desses setores devem se ampliar, com forte atuação de bloggers e outros atores dos meios de comunicação digital, que influenciam e informam os consumidores, multiplicando canais de relacionamento (Webshoppers, 2015 p.18).

Essa prevalência da categoria moda no topo da liderança comercial em ambientes digitais se dá igualmente em âmbito global. Em 2014, de acordo com o website Business Of Fashion (businessoffashion.com, daqui por diante mencionado por sua sigla, BOF), o grupo chinês Alibaba alcançou cerca de 21,8 bilhões de dólares na sua venda inicial de ações na Bolsas de Valores de Nova lorque, à medida que os investidores entenderam a importância do e-commerce para países emergentes como a China.

Por outro lado, o e-commerce hindu também está se aquecendo e a moda lidera as categorias de produto mais exitosas. Quando, em meados do mesmo ano, o grupo Flipkart adquiriu Myntra, maior e-tailer de moda da Índia, por 357 milhões de dólares, a empresa passou a dominar a maioria das categorias de e-commerce no subcontinente indiano, incluindo moda, o que coloca a empresa à frente de pioneiros como Amazon (BOF, 2014). Paralelamente, à medida que vemos a venda e 0 uso de aparelhos de dispositivos móveis com acesso à internet crescer no Brasil e no mundo, o comércio eletrônico móvel (ou m-commerce) também se torna uma forte tendência. As classes A e B são as que mais representam o consumidor do m-commerce, com $62 \%$ de participação, enquanto as classes C e D possuem $27 \%$. As mulheres são $57 \%$ deste público, sendo que a faixa etária que mais consome está entre 35 e 49 anos para ambos os sexos ( $39 \%$ das mulheres e $38 \%$ dos homens), e 40 anos é a média de idade (Webshoppers, 2015, p. 8).

0 aumento nas vendas de smartphones e de conexões de banda larga no Brasil justifica o crescimento vertiginoso do $m$-commerce. Com esse crescimento rápido, vemos a adoção do uso de telefones celulares e tablets para consulta de informações de produtos, comparação de preços e compra usando esses dispositivos móveis. E os gestores de varejo on-line precisarão organizar esse processo comunicativo de maneira eficiente nas mídias sociais digitais, utilizando multiplataformas e tecnologias emergentes.

Como já dito, a comunicação por meio das mídias sociais digitais é convergente, atraindo profissionais de vários setores diferentes: engenheiros, redatores, fotógrafos, stylists, produtores de conteúdo on-line, gestores de relacionamento em mídias sociais, analistas de métricas digitais e outros intermediários, que têm como papel alimentar a dimensão simbólica dos modos de vida presenciais em ambientes digitais, provocados pela explosão da economia criativa. Isso significa que novos espaços de relacionamento, desenhados a partir de anseios dos próprios usuários, estão mudando a paisagem social e impulsionando a necessidade de ofertas educacionais inovadoras. Pautada pela inteligência coletiva de que nos fala Lévy (2000, p. 28), emerge uma capacidade de organização não-linear, de contornos sutis, constantemente insuflada por uma vontade férrea de adesão maciça e líderes cujo carisma é pautado pelo fazer acontecer. Contudo, o modo pelo qual as oportunidades profissionais estão sendo desenhadas a partir de posturas empreendedoras em ambientes on-line sugere espaços em branco na formação superior.

0 intenso movimento comercial na internet demanda novos profissionais, gerando maior índice de empregabilidade, tanto quanto oportunidades para empreendedores. São esses sujeitos que a oferta de um Curso Superior de Tecnologia 
em Mídias Sociais Digitais busca formar, contribuindo, no âmbito da economia criativa, para a consolidação de novas profissões cuja demanda já é visível.

Trata-se de uma situação que a humanidade não experimenta desde o final da Idade Média e o início do Renascimento, do Novo Mundo e do lluminismo, a qual, portanto, requer atenção das instituições de ensino superior e incentiva novas políticas de atuação em mídias sociais digitais, de modo a ofertar a melhor educação formal possível para jovens que decidem seguir carreira nessa área. Um esforço consistente, que leve em consideração o ponto de vista da nova geração de estudantes que emerge nesse cenário, deve somar-se a uma visão analítica do papel da educação superior, consistente com as demandas da sociedade digital.

Com a evolução tecnológica, a necessidade de formação acadêmica e a inserção no mercado profissional das gerações $Y$ e $Z$, as multiplataformas digitais vêm paulatinamente se transformando em espaço crucial para a circulação de discursos ligados à moda e ao estilo de vida. Particularmente, como aponta a já citada Pesquisa de Hábitos de Mídia 2014, os blogs vêm se tornando elementos cruciais para o crescimento das plataformas digitais, apresentando uma nova noção de agilidade e negociação de tempo na disseminação de notícias e no endosso de produtos e serviços. A aparição de blogs no meio digital abriu portas para a criação de conteúdo individual, e oferece uma maneira fácil de acompanhar as novas tendências, à medida que elas surgem.

Todavia, os profissionais que optaram por essa atividade são pioneiros e, até o momento, não dispunham de formação superior compatível com as demandas da sociedade digital e com as oportunidades geradas pela economia criativa abordadas anteriormente. Por outra parte, essa mesma situação exige constante atualização das páginas e profundo repertório cultural, além de reflexos ágeis em termos de capacidade analítica e curatorial, bem como capacidade de monetização e geração de negócios sustentáveis. Esses critérios são alvo da matriz curricular de mídias sociais digitais e de seu conteúdo programático.

\section{CONSIDERAÇÕES FINAIS}

A convergência e o compartilhamento permeiam um novo mundo, construindo os pilares da sociedade digital e, precisamente, os cidadãos de hoje usam a internet - em tablets, smartphones ou computadores - para se envolverem em ações mediadas por pessoas e marcas que eles admiram e que os unem em comunidades com anseios compartilhados.

O compartilhamento torna-se o "meio" pelo qual ideias e ações podem trafegar para solucionar problemas, trazendo capacidade para todos agirem da melhor maneira a partir da análise das experiências do outro. Nesse sentido, ocorre um processo de ensino-aprendizagem coletivo, capaz de apontar potencialidades para novos campos de formação superior que considerem essas transformações.

Por outro lado, como já dito, as corporações vêm reconhecendo o valor da participação do consumidor nas mídias sociais digitais como um ativo econômico a ser corretamente gerenciado, ampliando a oferta de empregos no mercado de comunicação on-line. Mas as pessoas por trás das máquinas estão aprendendo como realizar suas atividades profissionais na prática, por meio de suas ações cotidianas.

Tal demanda propicia um novo cenário econômico, com ambientes de trabalho inéditos, que nos levam a pensar a comunicação on-line como atividade profissional e educativa diferenciada, capaz de criar uma sinergia entre processos de 
gestão e projetos, criação, negócios e entretenimento. Tratamos, portanto, da potencialização da economia criativa por meio de formação superior que capacite indivíduos para as transformações da sociedade digital.

Entende-se que é papel do ensino superior preparar os estudantes para as carreiras do futuro, que são flexíveis, globalizadas, inovadoras e focadas no mercado de trabalho. 0 Curso Superior de Tecnologia em Mídias Sociais Digitais reforça a articulação entre a prática profissional e a formação acadêmica de futuros profissionais que estarão aptos a gerenciar a inteligência coletiva em torno da inovação de produtos, serviços e modelos de negócios em ambientes digitais.

Tal posição expressa a dinâmica produtiva da economia criativa e da convergência das mídias em ambientes globalizados, podendo potencializar a inteligência coletiva. Muitas empresas podem se beneficiar da proposta de formação dessa natureza, sobretudo com o surgimento da chamada "internet das coisas", quando produtos de várias naturezas estarão interconectados entre si, a exemplo dos smartwatches, como o IWatch (Apple), e digital bracelets, como o MICA (co-brand entre as empresas Intel e Opening Ceremony), que acumulam funções de smartphones e com eles se conectam por meio de aplicativos. Também há indicativos de que serão facilitados com a introdução das impressoras 3D domésticas e drones no cotidiano.

Enquanto as impressoras 3D possivelmente permitirão ao usuário comprar projetos de design e imprimir o produto em si em sua própria residência ou em centros de impressão 3D próximos, revolucionando processos de manufatura industrial, os drones, dispositivos aéreos não tripulados comandados por controle remoto, possivelmente alterarão a logística de distribuição e a mobilidade urbana, com o envio de medicamentos a locais distantes, o controle de pragas agrícolas ou 0 resgate de feridos em alto mar.

Se a cartografia das relações humanas, tanto quanto a paisagem urbana, passam a enfrentar, cotidianamente, o desafio e a interferência crônica da vida on-line no mundo off-line, certamente essas relações também são refletidas na sociedade digital, gerando um fluxo contínuo de emaranhados e nós, ou pontos de encontro, nas redes sociais.

Exemplos dessa natureza apontam que, cada vez mais, o mercado de mídias sociais digitais exigirá de seus recursos humanos uma formação profissional que inclua conhecimentos estruturados, ligados ao estilo de vida da classe criativa. Todavia, atividades tão distintas entre si exigem formação multidisciplinar e matrizes curriculares que orientem a interligação entre conhecimentos para aplicação em ambientes digitais e reverberação na vida off-line. Trata-se de um grande desafio para as instituições de ensino superior, uma vez que, como apontado anteriormente, demanda matrizes curriculares com integração interdisciplinar de complexidade elevada, bem como maior proximidade com as indústrias criativas.

Em termos da dinâmica de ensino-aprendizagem, o entrosamento entre áreas de conhecimento tais como design e comunicação, tecnologia e arte, finanças e logística, entre outras, sugere a criação de um mosaico movediço de conhecimento, a ser articulado em torno de projetos que considerem a existência on-line tanto quanto a vida presencial. Mais até, indicam a necessidade de constante atualização dos conteúdos curriculares, em sinergia com a velocidade das próprias redes existentes na sociedade digital. Paralelamente, sugere que flexibilidade e agilidade em acompanhar essas transformações, tanto por parte das instituições de ensino quanto dos órgãos de regulamentação do setor, devem ser igualmente incorporadas como valor pelo corpo docente e discente.

\section{REFERÊNCIAS}

BAITELLO, Norval. O pensamento sentado: sobre glúteos, cadeiras e imagens. São Leopoldo, RS: Unisinos, 2009. 
BOX 1824. Projeto "Sonho brasileiro". São Paulo, 2012. Disponível em: <www.osonhobrasileiro.com.br>. Acesso em: 11 maio 2015.

CASTELLS, Manuel. A galáxia da internet. reflexões sobre a internet, os negócios e a sociedade. Rio de Janeiro, Zahar, 2003.

FECOMÉRCIO. Lançamento do Conselho de Economia Criativa. São Paulo, [s. d.]. Disponível em: <http://www.fecomercio.com.br/ arquivos/arquivo/Lancamento\%20do\%20 Conselho\%20de\%20Economia\%20Criativa_zzwzzg31a7.pdf>. Acesso em: 22 abr. 2013.

FIRJAN. Indústria criativa: mapeamento da indústria criativa no Brasil. Rio de Janeiro: Firjan, 2012.

FLORIDA, Richard. A ascensão da classe criativa. Porto Alegre: L\&PM Editores, 2011.

GOOGLE THINK. Renner éa primeira empresa brasileira a usar o Google Cardboard. Estudo de caso. São Paulo, 2015. Disponível em: <http://www.google.com.br/think/case-studies/renner-google-cardboard-brasil.html>. Acesso em: abr. 2015.

HOWKINS, John. Economia criativa: como ganhar dinheiro com ideias criativas. São Paulo: M. Books, 2012.

JENKINS, Henry. Cultura da convergência. 2. ed. São Paulo: Aleph, 2009.

KOTLER, Philip; KARTAJAYA, Hermawan; SETIAWAN, Iwan. Marketing 3.0: as forças que estão definindo o novo marketing centrado no ser humano. São Paulo: Elsevier, 2010.

LÉVY, Pierre. A inteligência coletiva: por uma antropologia do ciberespaço. 3. ed. São Paulo: Edições Loyola, 2000.

MOORE, Gwyneth. Promoção de moda. São Paulo: Gustavo Gili, 2013.

NIELSON, Jakob. How long do users stay on web pages. 12 Sept. 2011. Disponível em: <http://www.useit.com/alertbox/pageabandonment-time.html>. Acesso em: 4 out. 2011.

RECUERO, Raquel. Redes sociais na internet. Porto Alegre: Sulina, 2009.

ROCAMORA, Agnes. Blogs personnels de mode: identité et sociabilité dans la culture des apparences. Sociologie et Sociétés, v. XLIII, n. 1, p. 19-44, 2011

ROSA, Hartmut. Accélération: une critique sociale du temps. Paris: Découverte, 2010.

SANTAELLA, Lúcia; LEMOS, Renata. Redes sociais digitais: a cognição conectiva do Twitter. São Paulo: Paulus, 2010.

SECOM. Pesquisa de hábitos de mídia. Brasília: Secretaria da Comunicação Social da Presidência da República, 2014.

UNCTAD. The creative economy report 2010. [S. L.]. Disponível em: <http://unctad.org/fr/Docs/ditctab20103_en.pdf> . Acesso em: 10 abr. 2015.

WEBSHOPPERS. Relatório Webshoppers 2015. 31. ed. Disponível em: <www.ebit.com.br/webshoppers>. São Paulo: E-bit, 2015. Acesso em: 10 maio 2015.

Artigo recebido em 11.5.2015 e aprovado em 19.11.2015. 